\title{
Disputas de sentidos en las formas de habitar el mundo Una propuesta conceptual para (re) pensar el hábitat en términos interculturales
}

\author{
Disputes of the senses in the ways of inhabiting the world \\ A conceptual proposal to (re) think the habitat in intercultural terms
}

Por: Gonzalez, Facundo*

Instituto de investigaciones en Energía No Convencional (U.N.Sa/CONICET)

Salta, Argentina

Email: facundoinenco@gmail.com

https://orcid.org/0000-0002-1603-4235

Fecha de recepción: 3/04/2021

Fecha de aprobación: 19/05/2021

DOI: http://dx.doi.org/10.30972/nvt.1715350

\section{Resumen}

El artículo que aquí presentamos forma parte de un proceso de investigación/extensión que se extendió durante más de dos años en la Puna y en el Chaco salteños, en el norte argentino, con una interacción significativa con los pueblos Kolla de Hurcuro y Wichí de El Cocal (2017-2019). Pretendimos comprender las formas de producción de hábitat a partir del estudio de las relaciones expresadas en la configuración de las dimensiones supra e infra hábitat (Gonzalez, 2020) en el desarrollo de dos experiencias orientadas a la implementación de tecnologías basadas

\footnotetext{
* Este trabajo forma parte del grupo de investigación denominado Energía y Sociedad del INENCO. Retoma las experiencias de investigación y extensión de algunos de sus integrantes. Al mismo tiempo, los casos que disparan la presente reflexión teórica fueron objeto de análisis de una tesis doctoral del Doctorado en Estudios Sociales en América Latina de la Universidad Nacional de Córdoba (2020) que señalamos en la bibliografía adjunta.

* Doctor en Estudios Sociales de America Latina Magíster en Ciencia, Tecnología y Sociedad Diploma Superior otorgado por la Facultad de Periodismo y Comunicación (FPyC) de la Universidad Nacional de La Plata (UNLP) Licenciado en Ciencias de la Comunicación
} 


\section{Gonzalez Facundo}

en energías no convencionales en el territorio mencionado. Una particularidad de ambas experiencias se debe a que ambos proyectos pertenecen a la Universidad Nacional de Salta (UNSa) con dichas comunidades indígenas.

Con el objetivo de reconocer y comprender las formas específicas que presentan las configuraciones de supra e infra hábitat en las experiencias de producción de hábitat en la Puna y en el Chaco salteños (2017-2019) construimos un proyecto de investigación que responde a nuestros intereses políticos, epistemológicos y ontológicos. El diseño de la propuesta teórica-conceptual, que aquí presentamos, representa un esfuerzo que buscó dotar de pertinencia el proceso de investigación en relación con el objeto de estudio. Por esto revisamos críticamente la presencia de nociones "universales" en los análisis de producción de hábitat, incorporando la perspectiva de la opción decolonial y las epistemologías del sur al encuadre conceptual (Gonzalez, 2020).

Finalmente, la reflexión teórica que aquí presentamos pretende contribuir al desafío a las tradiciones hegemónicas y una apuesta epistémica que contribuya al desmontaje del Modelo Civilizatorio Moderno Colonial en el campo de estudios del hábitat.

Palabras clave: hábitat, sentidos, interculturalidad, MCMC, decolonialidad.

\section{Abstract}

The article that we present here is part of a research / extension process that lasted for more than two years in the Puna and Chaco of Salta, in northern Argentina, with significant interaction with the Kolla de Hurcuro and Wichí de El peoples. Cocal (2017-2019). We tried to understand the forms of habitat production from the study of the relationships expressed in the configuration of the above and below habitat dimensions (Gonzalez, 2020) in the development of two experiences aimed at the implementation of technologies based on unconventional energies in the mentioned territory. A particularity of both experiences is due to the fact that both projects belong to the National University of Salta (UNSa) with said indigenous communities. 
Disputas de sentidos en las formas de habitar el mundo

Una propuesta conceptual para (re) pensar el hábitat en términos interculturales.

In order to recognize and understand the specific forms that the supra and infra habitat configurations present in the habitat production experiences in the Puna and in the Salteño Chaco (2017-2019), we built a research project that responds to our political interests, epistemological and ontological. The design of the conceptual theoretical proposal, which we present here, represents an effort that sought to give relevance to the research process in coherence with the object of study. For this reason, we critically review the presence of "universal" notions in the analysis of habitat production, incorporating the perspective of the decolonial option and southern epistemologies to the conceptual framework (Gonzalez, 2020).

Finally, the theoretical reflection that we present here aims to contribute to the challenge to hegemonic traditions and an epistemic commitment that contributes to the dismantling of the Modern Colonial Civilization Model in the field of habitat studies.

Keywords: habitat, senses, interculturality, modern colonial civilizational model, decoloniality.

\section{Cómo citar este artículo:}

APA: Gonzalez, F. (2021). Disputas de sentidos en las formas de habitar el mundo Una propuesta conceptual para (re) pensar el hábitat en términos interculturales. Nuevo Itinerario, $17(1), 60-105$.

Las formas lineales de regulación social y la anulación de la imaginación como instancia de producción de formas de ser y de estar en el mundo debilitan y permean el MCMC. En ese marco, cómo se vive y en qué condiciones, son interrogantes que permiten reflexionar sobre la reinstalación de utopías latinoamericanistas, contrahegemónicas y situadas. No hablamos, sin embargo, de utopías originarias, pues creemos que la historia del vínculo colonial es una característica en la construcción del proyecto latinoamericano decolonial enclavado en el Sur Global, apoyado en la propuesta de Epistemología del Sur, como un Pensamiento Posabisal (Santos, 2018). 


\section{Gonzalez Facundo}

El proyecto de raigambre latinoamericano con alcance global no pretende abolir las expresiones de la razón indolente a la que Santos (2009) comprende como bases de racionalidad del Modelo Civilizatorio Moderno Colonial (MCMC) y que determina formas de concepción del espacio, del tiempo -entre otras-. Su pretensión es la de abonar al espacio para una interacción respetuosa y una ecología de prácticas, a través de la cuales cada una de las comunidades, convocadas a sumarse, pueda habitar su territorio de una forma distinta, diferente, transcendiendo las lógicas de producción de monocultura sostenidas por el MCMC, que producen formas únicas o unívocas de existir (Santos, 2009). Este sistema axiológico proporciona claves para el establecimiento de categorías que dan cuentan de nuestras realidades desde una perspectiva que necesariamente es intercultural.

El conocimiento sobre cómo viven las personas en contextos de diversidad cultural, en territorios marcados por tensiones entre actores que conciben el ser y estar en el mundo de formas diferentes y -a veces- contradictorias, con vinculaciones coloniales históricas, constituye un elemento de particular interés para nosotros. Para estudiar este tipo de escenarios partimos -conceptualmente- de la sociología de las ausencias -proveniente de la propuesta de epistemologías de sur- que busca restituir presencias en la experiencia social en conexión con una sociología insurgente, que dé cuenta de los procesos a partir de los cuales "lo que no existe", es producido activamente como no existente, como una alternativa no creíble, como una alternativa descartable, invisible a la realidad hegemónica del mundo" (Santos, 2006, p. 23). Finalmente, desde el abordaje conceptual de la sociología de las emergencias (Santos, 2009) buscamos reconocer y contribuir a la ampliación de las expectativas sociales de quienes habitan determinado territorio, permitiendo: “(...) abandonar esa idea de un futuro sin límites y reemplazarla por la de un futuro concreto, basado en estas emergencias: por ahí vamos construyendo el futuro" (Santos, 2006, p. 23).

La investigación de la que forma parte este artículo aborda dos experiencias de trabajo de la Universidad Nacional de Salta, con comunidades indígenas: por una parte, 1- el Proyecto de Extensión denominado "La Misión-Rivadavia: diagnóstico e intervención socio técnica para la mejora del hábitat de comunidades originarias Wichí 
Disputas de sentidos en las formas de habitar el mundo

Una propuesta conceptual para (re) pensar el hábitat en términos interculturales.

en el Chaco Salteño" y 2- el proyecto de mejora del hábitat denominado "Agua Caliente para los Hurcureños". Ambas experiencias se localizan en las zonas catalogadas como dos de las más pobres del país (INDEC, 2018): chaco salteño y puna salteña. Estas regiones además de caracterizarse por su diversidad cultural y ambiental presentan indicadores de desnutrición, salud, educación y acceso a la energía negativos: el chaco salteño muestra una de las tasas de mortalidad infantil más alta, mientras que en la puna salteña el acceso a la educación primaria es restringido a quienes se encuentran cerca de algún pueblo, por señalar dos aspectos que marcan fuertemente a estos territorios. Además, las disputas por la propiedad de la tierra, el avance de la frontera agraria/minera atentan y avasallan las formas de habitar de estas comunidades.

El Estado -en vinculación con el mercado- aborda estas situaciones desde una visión occidental que no ha dado resultados positivos pues la situación resulta cada vez más preocupante. De esta forma, la extensión del MCMC ha expulsado a las comunidades de sus tierras y las ha obligado a adoptar nuevas formas de habitar y a reconfigurar su vinculación con el ambiente, los criollos y otras comunidades. En este sentido, creemos que es posible reconocer (otros) elementos que den cuenta de ese proceso de colonización e imposición colonial y la consecuente incorporación al orden capitalista, revisando en los aportes del pensamiento social no hegemónico. Así, encontramos cómo "de repente" el pueblo Wichi es noticia por las muertes de niños por desnutrición "por cuestiones culturales", los caciques asesinados "por invadir propiedad privada"; sin considerar que el avance de la frontera agraria los expulsa del monte profundo .

El Proyecto de Extensión denominado "La Misión-Rivadavia: diagnóstico e intervención socio técnica para la mejora del hábitat de comunidades originarias Wichí en el Chaco Salteño", propuso estudiar las condiciones de hábitat de la comunidad y consistió en la transferencia de cocinas a base de biomasa en una escuela bilingüe de la comunidad "El Cocal" (Rivadavia Banda Sur) del noreste de la Provincia. El proyecto fue llevado adelante por el Instituto de Investigaciones en Energía No Convencional (INENCO) y la Asociación Civil Amtena (perteneciente a esa Comunidad Wichí), 


\section{Gonzalez Facundo}

financiado parcialmente con fondos del Programa "Compromiso Social Universitario" de la Secretaria de Políticas Universitarias de la Nación durante los años 2018 y 2019.

El proyecto de mejora del hábitat denominado "Agua Caliente para los Hurcureños", en la Comunidad Kolla de Hurcuro, se centró en la instalación de calefones solares para la provisión de agua caliente en las viviendas de la comunidad, y la generación de capacidades locales irradiadas a partir de la capacitación en el armado y mantenimiento de los calefones. Hurcuro está ubicada en la zona de la Puna salteña a $4000 \mathrm{msnm}$, a $30 \mathrm{~km}$ de San Antonio de los Cobres (Departamento de Los Andes). La financiación de este proyecto provino de la Secretaría de Extensión de la Universidad Nacional de Salta y se ejecutó durante el año 2018.

Ambas experiencias parten de proyectos de extensión/transferencia de una Universidad Nacional argentina y emergen como espacios que permiten mirar la (re) producción de sentidos de hábitat en actores culturalmente diferentes al occidental.

Somos conscientes de que el registro de experiencias es una manera de aproximarse al reconocimiento de las marcas del MCMC, que hegemoniza las formas de habitar nuestro territorio, y que pueden ejemplificarse en los modos de producción de la ciudad/ hábitat urbano. Pero también consideramos esencial la comprensión de las formas de hábitat de comunidades no urbanas, que no se enmarcan en la forma binaria de pensar lo urbano/rural. Las comunidades indígenas expresan un ejemplo paradigmático de resistencia al MCMC desde los inicios de la colonización. Aunque esto no implica que los pueblos indígenas permanezcan inmutables -como tampoco los colonizadores- desde el momento de la colonización.

Así, si entendemos hábitat como una territorialidad, marcada por la experiencia de habitar, concebido desde el ejercicio de producción y reproducción de sentidos que cristalizan en dimensiones supra e infra hábitat, entonces el hábitat se configura en este trabajo como un objeto doblemente descentrado. Lo supra hábitat refiere a los designios del MCMC, expresado en lógicas de producción de monocultura y formas de pensamiento abisal (Santos, 2009). Mientras que la dimensión infra representa elementos del hábitat asociados a la memoria y a la resistencia, posibles de visualizar 
Disputas de sentidos en las formas de habitar el mundo

Una propuesta conceptual para (re) pensar el hábitat en términos interculturales.

mediante el trabajo de traducción intercultural y el diálogo de saberes (Gonzalez, 2020; Gonzalez, 2019).

Se subraya el carácter no dado del hábitat, la experiencia de habitar y en ese sentido, el enfoque comunicacional de producción de sentidos nos permite ingresar desde una perspectiva privilegiada a ese proceso de construcción de territorio/hábitat.

Dada la especificidad de las experiencias que se estudian, la perspectiva de las epistemologías del sur y el enfoque de Comunicación desde la interculturalidad (Walsh, 2010) permite entender el interjuego de producción de sentidos supra e infra hábitat que componen la experiencia de habitar esos territorios.

El desarrollo teórico que presentamos a continuación es producto de la dialéctica entre revisión de la literatura, reconocimiento de enfoques, selección de categorías y construcción del caso a estudiar. Esto se dio en paralelo con la construcción del objeto de estudio, expresado en: "la configuración de las dimensiones supra e infra hábitat en el desarrollo de dos experiencias orientadas a la producción de hábitat en la Puna Salteña y el Chaco Salteño (2017-2019)”. Así dada la edificación del objeto, pretendimos ajustar el enfoque conceptual que planteamos y ponemos a consideración.

SOBRE LOS ESTUDIOS DE HÁBITAT: ALGUNAS NOCIONES Y PROPUESTA DE TRAYECTORIA

Con el objetivo de examinar las categorías conceptuales previas o que contribuyeron a la conformación de la categoría Hábitat -tal y como la asumimos en este trabajo- nos proponemos abordar reflexivamente la problemática, poniendo foco en ciertos paradigmas surgidos en el tiempo. Estos enfoques pretendían explicar y comprender las transformaciones que se iban sucediendo en las ciudades y otros espacios, sus resultados, modos de producción y validación de modelos y teorías.

Para cumplir con el objetivo expresado, es imperioso revisar procesos históricos que tuvieron incidencia en las formas de producción de hábitat, en sus estructuras económicas, políticas y sociales y en las relaciones que se fueron estableciendo entre ellas. 
Sobre las perspectivas, destacamos el trabajo de Liliana Aguirre y Mónica Burmester (2014), quienes sistematizan de modo claro algunas de las principales teorías que aportaron al campo del hábitat:

Tabla 1. Teorías que aportaron a los estudios del hábitat.

\begin{tabular}{|c|c|c|}
\hline Eventos - Años & Teorías del concepto de hábitat & Categorías \\
\hline $1960 / 1970$. & $\begin{array}{l}\text { Teoría de la modernización } \\
\text { Nació la propuesta de participación } \\
\text { popular } \\
\text { Planificación tradicional } \\
\text { Teoría del Desarrollo. (Take off) }\end{array}$ & $\begin{array}{l}\text { Dicotomía: rural -urbana } \\
\text { Las condiciones del } \\
\text { despegue }\end{array}$ \\
\hline $\begin{array}{l}\text { 70/80 } \\
\text { Declaración de } \\
\text { “Cocoyoc". ONU. } \\
\text { (1974) } \\
\text { Informe Brundtland } \\
\text { (1987) } \\
\text { Hábitat I. Vancouver } \\
\text { ONU (1976) }\end{array}$ & $\begin{array}{l}\text { Teoría de las Necesidades Básicas. (Basic } \\
\text { need) } \\
\text { Teoría del Desarrollo y Medio Ambiente } \\
\text { Pedagogía de la Liberación } \\
\text { Investigación Acción }{ }^{2} \\
\text { Constructivismo (Metodología de los } \\
\text { Sistemas Complejos) } \\
\text { Teoría del Desarrollo Estructuralista. }\end{array}$ & $\begin{array}{l}\text { Se debilita la noción de } \\
\text { progreso. } \\
\text { Se incorporan los DDHH } \\
\text { y el derecho a la } \\
\text { participación. } \\
\text { Desarrollo Sustentable } \\
\text { Planificación del } \\
\text { territorio. } \\
\text { Participación. } \\
\text { La reproducción en las } \\
\text { relaciones de } \\
\text { dominación }\end{array}$ \\
\hline $\begin{array}{l}\text { 90/2000 } \\
\text { Hábitat II. Estambul. } \\
\text { (1996) } \\
\text { Democracia- en A. L. } \\
\text { Neoliberalismo } \\
\text { Pos - fordismo }\end{array}$ & $\begin{array}{l}\text { Teoría del Desarrollo Historicista } \\
\text { Modo de Producción Social del Hábitat. } \\
\text { (Inv empírica) } \\
\text { La reproducción social en el campo del }\end{array}$ & $\begin{array}{l}\text { Espacio -temporal } \\
\text { Desterritorialización, } \\
\text { relocalización. } \\
\text { Estudio de "lo local" } \\
\text { Reproducción de las } \\
\text { relaciones de } \\
\text { dominación Noción de la } \\
\text { Dependencia. } \\
\text { Peri urbano: Interfase }\end{array}$ \\
\hline
\end{tabular}

${ }^{1}$ El origen se remonta al proceso de descolonización o independentistas de antiguas colonias en el continente africano y asiático. Y otros países con necesidades de respuestas rápidas al sector de salud, educación, ecología y hábitat entre otras problemáticas.

${ }^{2}$ La interdisciplina de Piaget, la Investigación-Acción de Fals Borda y la pedagogía del oprimidoeducación popular de P. Freire constituyen contribuciones y experiencias que abordan lo complejo y permiten experimentar métodos y avanzar en articulaciones múltiples (Poggiese, 2009).

${ }^{3}$ La interdisciplina de Piaget y Rolando García. 
Disputas de sentidos en las formas de habitar el mundo

Una propuesta conceptual para (re) pensar el hábitat en términos interculturales.

\begin{tabular}{|l|l|l|}
\hline & $\begin{array}{l}\text { espacio urbano. } \\
\text { Teoría posestructuralista europeo. }\end{array}$ & $\begin{array}{l}\text { rural urbano. } \\
\text { Morfologia de } \\
\text { arquipélago urbano. } \\
\text { Los lugares y no Lugares } \\
\text { Lo local y lo global. }\end{array}$ \\
& $\begin{array}{l}\text { Escenarios de planificación -gestión. } \\
\text { Participación Estratégica. Universidad de } \\
\text { Harvard }\end{array}$ & $\begin{array}{l}\text { Actores Sociales } \\
\text { Gestión asociada e intersectorial } \\
\text { Planificación Estratégica Situacional. } \\
\text { (CEPAL) }\end{array}$ \\
$\begin{array}{l}\text { Continúa. Metodologías de PPGA: } \\
\text { Planificación participativa y Gestión } \\
\text { asociada. (UNESCO- FLACSO) }\end{array}$ & $\begin{array}{l}\text { Planificación Estratégica } \\
\text { (FODA) }\end{array}$ \\
\hline $\begin{array}{l}\text { Post convertibilidad en } \\
\text { Argentina }\end{array}$ & $\begin{array}{l}\text { Genera escenarios que } \\
\text { consolidan a actores } \\
\text { sociales territoriales que } \\
\text { ejercen influencia sobre } \\
\text { temas de la ciudad. } \\
\text { Planificación estratégica. } \\
\text { Modelo FODA. }\end{array}$ \\
\hline
\end{tabular}

Fuente: Aguirre, Liliana; Burmester, Mónica, 2014

La Tabla $\mathrm{N}^{\circ} 1$ permite observar las teorías y metodologías sociales que sostuvieron la forma de comprensión del hábitat y el ambiente, señalando aquellas que fueron significativas en el trabajo de diseño de políticas públicas interdisciplinarias.

De esta forma trataban de entender las categorías conceptuales que se utilizaban para explicar la sociedad, la cultura y las instituciones de Latinoamérica. Así, podemos señalar la Conferencia sobre Urbanización en América Latina realizada en Santiago de Chile en 1959 donde se discutieron las implicancias sobre la problemática del hábitat, de distintas posiciones -aunque todas occidentales u occidentalizadas-.

Desde 1966 se organizaron varias actividades académicas sobre las ciudades en América Latina donde participaron académicos, cientistas sociales y ensayistas, en

\footnotetext{
${ }^{4}$ Entre las figuras más importantes de esta corriente se incluyen a Alain Touraine, Alberto Melucci y Ernesto Laclau. Siendo el interés de esta postura las cuestiones de identidad y conciencia que nos brindan herramientas para analizar los movimientos sociales.
} 


\section{Gonzalez Facundo}

conjunto con decisores políticos. Una conferencia destacada, por las pretensiones de sus objetivos, fue la denominada "Repensar la ciudad de América Latina", realizada en Woodrow Wilson International Center for Scholars, Washington, en junio de 1986.

En el presente siglo se han realizado diversos encuentros internacionales sobre las consecuencias de la globalización en el territorio y en las ciudades. Algunos de esos eventos fueron organizados por la Asociación Internacional de Sociología (Amsterdam, 2011), Seminario de la Red Iberoamericana de Globalización y Territorio en México, Cuba, Brasil y Argentina (2000-2004) y las actividades de los grupos de trabajo Desarrollo Urbano del Consejo Latinoamericano de Ciencias Sociales (CLACSO) en Río de Janeiro, Quito y La Paz (2000-2014) (Veiga, 2009).

Otro actor referente para el diseño y gestión de modelos de producción de hábitat es la Organización de Naciones Unidas (ONU). A través de las conferencias de este organismo sobre Asentamientos Humanos, el Hábitat y el Medio Ambiente configuran escenarios políticos internacionales donde se promueven un conjunto de instrumentos para mejorar el proceso de gestión urbana de las ciudades que pertenecen a lo que ellos llaman "tercer mundo".

La declaración de Cocoyóc (1974) señaló que el desarrollo no puede limitarse a la satisfacción de las necesidades básicas y que es esencial prestar atención a necesidades vinculadas con la participación, libertad de expresión, recreación, derechos humanos y a un medioambiente sano.

Por su parte, en la Conferencia de Vancouver ONU Hábitat I se reconoce el crecimiento de la problemática de los asentamientos humanos en los países "del tercer mundo". Allí se plantea cómo desarrollar la cooperación internacional en esta problemática. El mencionado documento, incluye entre las causas y problemas del hábitat los orígenes de la pobreza (desarrollo económico inequitativo); deterioro social, ecológico, ambiental; tendencia del crecimiento demográfico mundial, urbanización improvisada, atraso rural y migración involuntaria por razones étnicas, raciales y económicas (ONU HÁBITAT, 2018).

Dicha declaración visibilizaba la crisis del hábitat, enfatizando la problemática habitacional con el objetivo de encontrar soluciones rápidas. Esto contribuyó a poner 
Disputas de sentidos en las formas de habitar el mundo

Una propuesta conceptual para (re) pensar el hábitat en términos interculturales.

de relieve los problemas comunes con cierta similitud de enfoques, especialmente en relación con el concepto de asentamientos humanos. La cuestión agrietó el paradigma hegemónico de aquel momento, basado en la dicotomía rural/urbano (Wirth, 1938), tradicional/moderno, Folk/Urbano (Redfield, 1941), de la Escuela de Chicago.

Durante los años 70-80 la Oficina Internacional de Hábitat I recomienda a los organismos internacionales financiar las pequeñas acciones, flexibilizar las normas de construcción y de uso de suelo, y estimular la organización comunitaria para la provisión de infraestructura y equipamiento (ONUHABITAT, 2018).

El tercer evento fue la Segunda Conferencia de las Naciones Unidas sobre los Asentamientos Humanos (Hábitat II), llevada adelante en Estambul en 1996, donde se destacaron dos temas de igual importancia a escala mundial: 1) "vivienda adecuada para todos" y 2) "desarrollo sostenible de los asentamientos humanos en un mundo en proceso de urbanización".

Sobre Hábitat II podemos destacar la pretensión de apertura del proceso preparatorio a lo largo de la década del 90 y los efectos de las políticas neoliberales en el campo del hábitat popular.

En América Latina, en ese período, se intensificaron esfuerzos de conceptualización y debate sobre la producción social del hábitat (PSH) a partir de la reflexión de sus organizaciones, con base en las experiencias que sus diversos miembros vienen transitando en el continente a lo largo de casi 40 años (Aguirre y Burmester, 2014).

En el contexto de los años 90, las sociedades occidentales (consideradas hegemónicamente- como las desarrolladas, modernas, democráticas, etc.) plantean una apertura de las economías, pero en esta interacción se produce una batalla desigual entre los más fuertes (Norte Global) y los más débiles (Sur Global) ya que las reglas son impuestas vertical y parcialmente. El hábitat continúa agudizándose como problema principal en los sectores más pobres (Romero, 2008). Cabe destacar los efectos negativos a causade las políticas neoliberales en la región, especialmente en el llamado campo del hábitat popular, conceptualizando prácticas y debates (en la academia y organizaciones de base). Se acuña el concepto de producción social del 


\section{Gonzalez Facundo}

hábitat, considerado como uno de los temas estratégicos de la resistencia a los efectos de las políticas neoliberales (Di Virgilio y Rodríguez 2009).

Por su parte, la teoría del cambio conceptual trabaja la reconstrucción de relaciones empíricas relevantes para los investigadores, y no tiene sentido sin estas. En cambio, las preguntas epistemológicas están orientadas al sentido de la elaboración teórica, a los conceptos, así como a sus relaciones con tesis epistemológicas y ontológicas que subyacen a la producción de la teoría (Castorina y Carretero, 2012).

En este punto se hace referencia a las trayectorias habitacionales (Aguirre y Burmester, 2014) transitadas por los actores sociales. Algunas de las propuestas teóricas tienen sus orígenes en las ciencias sociales (sociología, antropología e historia). En los últimos años, esos campos coincidieron en prestar atención al problema de la génesis e imbricación de las categorías espacio y tiempo en la vida social contemporánea. Tales categorías se han vuelto relevantes para analizar y reflexionar sobre las transformaciones ocurridas a partir de los años 80 , tendiendo a propiciar el surgimiento de una nueva y peculiar articulación espacio-temporal cuyos múltiples aspectos pretenden aprehender conceptos tales como: no lugares, espacio de los flujos, desterritorialización o deslocalización (González, 2019). Dichos términos connotan una cierta priorización analítica de la dimensión espacial, la cual, en contraste con la dimensión temporal, estuvo relegada a un segundo plano por la teoría social y por la totalidad de las disciplinas, a excepción de la geografía (González, 2019).

Queremos cerrar este apartado haciendo mención a las perspectivas de buen vivir o sumak kawsay (quechua) en Ecuador y el suma qamaña (aymara) que es el vivir bien en Bolivia, como aporte de los pueblos indígenas andinos de América Latina:

“Estos conceptos son una simplificación para la construcción del significado en la lengua española, luego de la traducción desde las lenguas aymara y quechua (que tienen otras significaciones implicadas en los vocablos previamente descriptos). Cada pueblo indígena tiene su expresión cultural propia y con el término "buen vivir" no se busca reproducir esta cosmovisión como una receta aplicable a otras comunidades, sino comprender enfoques latinoamericanos de abordar al hábitat popular." (Miranda Gassull, 2017, p.13) 
Disputas de sentidos en las formas de habitar el mundo

Una propuesta conceptual para (re) pensar el hábitat en términos interculturales.

Existen tres formas de abordar al buen vivir: a partir de las ideas, los discursos y las prácticas:

"La primera es el cuestionamiento radical a las ideas del desarrollo, y el segundo se aparta de los discursos que fomentan el progreso imbricado en el crecimiento, abriendo la posibilidad a pensar, escribir, hablar del mundo desde otra perspectiva. El tercero se refiere al planteo de proyectos políticos y normativos que propone el buen vivir" (Gudynas, 2011, p. 2)

Así vemos cómo la mayoría de las perspectivas comprenden al hábitat como un componente dado, apropiado, de arriba hacia abajo. Totalmente distanciado de la forma en como construimos su conceptualización en este trabajo.

No obstante, debemos reconocer las perspectivas que propusieron los pueblos indígenas andinos de Bolivia y Ecuador en asociación con el Estado Nacional. Vemos allí un antecedente más cercano al ideal de lo que consideramos hábitat, aunque la vinculación con los gobiernos que apoyaron esas perspectivas pareciese significar un límite, por las mismas naturalezas del Estado como actor colonial y capitalista: en Ecuador, el fin del gobierno de Rafael Correa implicó un retroceso en algunas conquistas ganadas por el movimiento indígena y, en Bolivia, el derrocamiento de Evo Morales pretendió ir en el mismo sentido.

DE LA “UNIVERSALIDAD” DEL/COMO MCMC ...

Para referir a nuestra posición paradigmática consideramos importante problematizar la noción de universalidad, lo que ayudará en la comprensión del MCMC. En este contexto, ponemos en cuestión que haya una aplicación de la verdad, la validez y la rectitud que pueda considerarse universal.

Con este fin retomamos, en primer lugar, la problemática del lenguaje en relación con la universalidad de los conceptos. Dice Friedrich Nietzsche:

“El lenguaje no se origina de modo lógico y todo el material con que más tarde trabaja el hombre de la verdad, el investigador, el filósofo, si bien no proviene del reino de lo utópico, tampoco procede de la esencia de las cosas." (Nietzsche, 1973, p. 75). 


\section{Gonzalez Facundo}

La suposición de que palabras como verdad, universalidad, civilización, razón, etc., tengan asociados respectivos conceptos en las diferentes lenguas, supone a la vez, un efecto de lenguaje que identifica una forma de pensamiento que puede resultar ajena para muchos pueblos.

Por su parte, Wittgenstein en el primer inciso de su Tractatus lógicophilosophicus sostiene que: "El mundo es todo lo que acaece. El mundo es la totalidad de los hechos, no de las cosas" (Wittgenstein, 2003, p. 49). La palabra como cosa, requiere inmediatamente el concepto, la definición, que necesariamente es una abstracción y que deja de lado lo particular. En este sentido, podríamos cuestionarnos qué particularidades se ocultan en los sustantivos arriba mencionados, teniendo en cuenta que han sido aplicados como absolutos desde la modernidad.

Por ejemplo, cuando hace 2.500 años Parménides transforma el hecho de ser en "el ser", produce un efecto de lenguaje sobre el cual se edifica toda la filosofía posterior. Cabe preguntarse merced a qué efecto, el ser humano concibe la idea de que hay una única verdad o una verdad absoluta que es universal, o que hay algún sustrato -también absoluto- que nos liga a una razón o a una universalidad. Consideramos que esto se produce como consecuencia de la oportunidad que tuvo Europa de expandir su poder político, económico, religioso, etc. y con ello la posibilidad de instaurar su verdad, su civilización, su razón, como universales. Además, el concepto filosófico que justifica la superioridad que se atribuye el Eurocentrismo se podría rastrear a través de lo que manifiesta Wittgenstein en el prólogo del Tractactus: “El libro trata los problemas filosóficos y muestra -según creo- que el planteamiento de estos problemas descansa en la incomprensión de la lógica de nuestro leguaje. Cabría acaso resumir el sentido entero del libro en las palabras: lo que siquiera puede ser dicho, puede ser dicho claramente; y de lo que no se puede hablar hay que callar" (Wittgenstein, 2003, p. 47). La superioridad de la que tratamos, basada en conceptos de verdad, de razón, de derecho, no puede ser explicada más que como un efecto de lenguaje, ya que no existe lenguaje lógico de justificación de hechos que permitan remitir a estos conceptos - o a estas cosas- como aquello que se puede decir claramente. 
Disputas de sentidos en las formas de habitar el mundo

Una propuesta conceptual para (re) pensar el hábitat en términos interculturales.

En este sentido, señala Stefan Jonsson que el universalismo aparece como un "significante supuestamente autoevidente (...) El pensamiento europeo fundamentó la universalidad en una noción específica de sujeto humano" (Jonsson, 2010, p. 111). Sujeto del cogito, que existe porque piensa y piensa de determinada manera autorreferencial, que posibilita una conciencia que se supone única, capaz de desarrollar un conocimiento verdadero de la realidad y formular leyes universales en consecuencia.

La conquista de Latinoamérica permite concretar la supremacía de Europa: "Su superioridad será, en buena parte, fruto de la acumulación de riqueza, experiencia, conocimientos, etc., que acopiará desde la conquista de Latinoamérica" (Dussel, 2000, p. 29). Las nociones de razón y verdad, por ejemplo, fueron extrapoladas a un continente donde carecían de todo sentido o significación. El convencimiento europeo del carácter civilizatorio de la modernidad llegó al extremo de culpabilizar a esa alteridad por resistir u obstruir el proceso que Europa sentía que estaba llamada a concretar: extender su civilización universalmente como la única verdad posible. Así se justifica la violencia, las víctimas son culpables y la estrategia civilizatoria moderna es inocente (Rodríguez, 2018). Esta forma de pensamiento abisal (Santos, 2009) se compone a partir de un sistema de distinciones visibles e invisibles, donde las invisibles fundamentan las visibles: "el universo de este lado de la línea, de la metrópoli; y el universo del otro lado de la línea, del espacio colonizado." (Santos, 2018, p. 28). Este convencimiento europeo, fundacional de la modernidad, construye a los sujetos -no europeos- como objetos de los que se habla y separa radicalmente el mundo metropolitano y el mundo colonizado.

EI MCMC también se tradujo en políticas de hábitat, estableciendo modelos "universales" de cómo habitar los territorios. En ese sentido, la ponderación de la "problemática del acceso a la vivienda" como una "problemática de hábitat" se aborda homogéneamente sin mucha distinción entre aspectos ambientales o culturales. Esta forma de abordaje de la política pública impone el modelo occidental de "vida digna", anulando -o desacreditando- materialidades y prácticas propias de cada comunidad. Así vemos cómo el Estado -casi- borró del paisaje de viviendas de la comunidad Kolla 


\section{Gonzalez Facundo}

de la Puna salteña, las estructuras de adobe o la utilización de bambú con galerías en las comunidades Wichí, por viviendas "Ilave en mano" del tipo occidental a base de ladrillo y cemento. Este ejemplo no sólo expresa un atropello a la cultura local de las comunidades, sino también un despropósito respecto de la climatización de las viviendas en relación a las características naturales circundantes, por mencionar sólo algunos rasgos. Se evidencia entonces cómo bajo el concepto de "vida digna" pretendidamente universal- se somete a condiciones de vida que anulan aspectos esenciales del hábitat de cada comunidad .

Como hemos mencionado, la conciencia de una razón universal que le es propia al pensamiento occidental se pone de manifiesto en la conquista y colonización de América Latina. Aunque los ideales de la ilustración manifiestan la dignidad del Otro en el plano ético, los mismos no se aplicaron en la colonización de América Latina y, muy por el contrario, sirvieron para justificar la negación del Otro en su humanidad (Rodríguez, 2018).

Este orden de cosas garantiza la pervivencia del esquema universalista que salvo algunos focos de resistencia como el movimiento zapatista- nos encuentra a todos asimilados a su concepción bajo el yugo del colonialismo, el sometimiento del capitalismo o el ordenamiento social del patriarcado. Como dice Jonsson: "la ideología del universalismo, diseminada desde arriba, mantiene su hegemonía únicamente en tanto que puede activar la utopía de la universalidad, que emerge desde abajo" (Jonsson, 2010, p. 120). El Estado, como actor moderno, sigue imponiendo el orden colonial y capitalista, como facetas del MCMC.

...A LA DECOLONIALIDAD COMO PROYECTO POLÍTICO/EPISTÉMICO DE ALCANCE GLOBAL...

El MCMC imposibilita la co-presencia de los dos lados de la línea (pensamiento abisal) y la traducción entre realidades y saberes que lo conforman. Esta característica, que Santos (2018) denomina Arrogancia Ignorante, abona al agotamiento de su legitimidad, socavada por diferentes actores en diferentes tiempos desde diferentes planos. Sus diferentes facetas están en cuestión y gran parte de esa situación es visible en los esfuerzos de autores críticos latinoamericanistas que propusieron reconfigurar 
Disputas de sentidos en las formas de habitar el mundo

Una propuesta conceptual para (re) pensar el hábitat en términos interculturales.

la forma en que se (auto) representa América Latina, logrando a su vez impacto y permanencia en el pensamiento mundial. Las propuestas en este sentido son: la Teología de la Liberación, la Pedagogía del Oprimido, la Teoría de la Dependencia y la Perspectiva Decolonial sostenida -mayormente- en la formulación de Aníbal Quijano sobre la Colonialidad del Poder.

La Opción Decolonial permite, entre otras posibilidades, dar cuenta críticamente de las significaciones que la modernidad produce en quienes la experimentan en condición de subalternos. Esto implica situar la conquista de América (1942) como un posible origen de la configuración moderna del mundo. Para esto resulta necesario caracterizar la modernidad como proceso geopolítico a partir de cuatro perspectivas que, de acuerdo con Arturo Escobar (2003), caracterizan la imagen de la modernidad:

- La mirada histórica sitúa el inicio de la modernidad en el siglo XVII a partir de hitos como la Revolución Francesa, la llustración y la Reforma. Observamos que todo el proceso -que luego se consolidaría con la Revolución Industrial- se concentra en Europa Occidental (Francia, Alemania e Inglaterra).

- Desde la perspectiva sociológica, es durante la modernidad que surgen instituciones emblemáticas como el Estado-Nación. Aunque en el mismo marco histórico se produce una creciente determinación de lo local por lo translocal y la dislocación de la relación espacio/tiempo.

- Desde una perspectiva cultural, la modernidad produce una jerarquización del saber científico como forma universalmente válida de producción de conocimiento .

- Desde una perspectiva filosófica, se caracteriza por la ponderación del hombre, como fundamento de todo conocimiento y orden social, escindido de toda naturaleza y deidad.

A partir del reconocimiento de estas características podemos señalar dimensiones, diversas y complementarias, del proyecto geopolítico moderno, apoyadas en la propuesta de Colonialidad del Poder entendida como la interrelación entre formas de explotación y dominación. 


\section{Gonzalez Facundo}

Los ejes argumentales de la Colonialidad del Poder se apoyan en una perspectiva que es a la vez epistémica/teórica/política/ética/estética. Al respecto, y con la ayuda de una sistematización de Segato (2018) en la que sintetiza el corpus de aportes que constituyen la propuesta de Quijano, podemos decir que la colonialidad y la modernidad son los dos ejes constitutivos del capitalismo y ambos configuran un patrón de poder, que se expande a todo el mundo a partir del proceso de colonización de América (Quijano, 2000).

Además, Quijano propone invertir el orden de precedencia de una historia solidificada: América inventa Europa no sólo a partir de los metales que constituyeron su riqueza de "acumulación originaria" sino que el "nuevo continente" emerge como un espacio que reconfigura las tradiciones europeas y sienta las bases para la modernidad futura (Segato, 2018). Antes de 1492 no existía Europa, ni España, ni América, ni "indios", "negros" o "blancos", categorías que vincularon pueblos con culturas muy diversas. Así, encontramos en la emergencia de América un punto para (re) pensar la constitución del mundo moderno. Del mismo modo que hallamos en proceso de conquista y colonización, las células primarias del capitalismo.

En ese primer momento fue la "racialización de las relaciones de dominación" lo que permitió legitimar el carácter eurocentrado del patrón de poder en los planos materiales como intersubjetivos. Este primer orden distinguía las diferentes identidades sociales y geo culturales y las ordenaba jerárquicamente bajo argumentos biologicistas. Como derivación del periodo colonial se consolida “(...) una concepción de la humanidad según la cual la población del mundo se diferencia en inferiores y superiores, irracionales y racionales, primitivos y civilizados, tradicionales y modernos" (Quijano, 2000, p. 344).

Resulta central en las discusiones del presente la desconfianza de Quijano ante el Estado -tanto en sus versiones capitalistas como socialistas-, ya que lo reconoce como un actor de disciplinamiento colonial. Sugiere Quijano (1990) que las acciones de la sociedad deben acontecer en todos los frentes, fuera y dentro del campo estatal, por caminos y brechas múltiples y simultáneas . 
Disputas de sentidos en las formas de habitar el mundo

Una propuesta conceptual para (re) pensar el hábitat en términos interculturales.

Otro eje argumental de Quijano sostiene la Colonialidad del Saber cómo una noción que, siguiendo a Lander (2000), da cuenta de una geopolítica del conocimiento, cuya hegemonía epistémica surge del singular poder de nombrar por primera vez, de crear fronteras, decidir cuáles saberes y conductas tienen estatus de conocimiento y por lo tanto son legítimos o no y establecer la propia mirada sobre el mundo como la mirada central y dominante.

También se incorpora en la construcción de la perspectiva la Colonialidad del Ser para explicar el modo con que la colonialidad se traduce en experiencia de vida, ya que los efectos de la colonialidad alcanzan la constitución ontológica de las personas que entran en el vínculo de la diferencia colonial. Así, entendemos Diferencia Colonial (Mignolo, 2003) como un concepto que alude al lugar y a las experiencias de aquellos actores que han sido objeto de inferiorización (Indígenas, afrodescendientes, movimientos antisistémicos, mujeres, homosexuales, etc.) Esto es tanto para los sectores dominantes como para los dominados. En definitiva, se propone un análisis de la diferencia ontológica colonial (Maldonado Torres, 2007; Escobar, 2003).

Otros ejes argumentales -a partir de los aportes de diversos autores- sobre la noción de colonialidad, permiten recuperar operaciones epistemológicas que estructuran la diferencia colonial como característica de la colonialidad del poder. En este sentido, Mignolo (2003) plantea el reconocimiento de la colonización del tiempo, la colonización del espacio y la negación de la contemporaneidad como componentes de la mirada eurocentrada del mundo. Hallamos gran parte de las características del colonialismo -primera faceta del MCMC- a partir de la propuesta de colonialidad del poder de Aníbal Quijano.

La segunda faceta del MCMC es el sistema capitalista al que Mignolo (2016) caracteriza como mundo moderno/colonial. Para ello, emplea como punto de partida la categoría de sistema-mundo moderno (Wallerstein, 1995), incorporando el concepto de colonialidad como el otro lado (uno oscuro) de la modernidad. Sostiene su propuesta apoyándose en la colonialidad del poder de Quijano, pero incorporando la diferencia colonial como un elemento más que amplía el imaginario capitalista en el marco del sistema mundo moderno: 


\section{Gonzalez Facundo}

"Con ello no quiero decir que la metáfora sistema-mundo moderno no haya considerado al colonialismo. Todo lo contrario. (...) Lo que si afirmo es que (...) deja en la oscuridad la colonialidad del poder (Quijano, 1997) y la diferencia colonial. En consecuencia, sólo concibe al sistema-mundo moderno desde su propio imaginario, pero no desde el imaginario conflictivo que surge con y desde la diferencia colonial" (Mignolo, 2016, p. 75).

Así, junto al patriarcado, reconocemos la relación íntima y entrelazada entre las tres facetas del MCMC, aunque las formas de articulación hayan variado a lo largo del tiempo. Sobre esto, Santos dice que:

"El fin de colonialismo formal, o político en sentido estricto no significó el fin del colonialismo social, cultural y, por lo tanto, político en sentido amplio. El proyecto colonial continúa hoy en vigor bajo nuevas formas y puede incluso afirmarse que su articulación con el capitalismo global nunca fue tan intensa como ahora." (2009, p.1213).

\section{...FORMANDO PARTE DE UNA EPISTEMOLOGÍA DEL SUR...}

La posibilidad de habilitar diálogos con la alteridad no eurocéntrica, a la vez que una crítica de las situaciones por las que los subalternos fueron sometidos, posibilita lo que Dussel (1999) denomina una transmodernidad. Por ello, resulta central la incorporación de los contradiscursos de la alteridad constitutiva de la modernidad. La transmodernidad es entendida como un proyecto político, económico, ecológico, pedagógico y religioso de realización de lo que es imposible cumplir para la modernidad por sí misma:

“(...) esto es una solidaridad incorporativa que he llamado analéctica, entre centro/periferia, hombre/mujer, diferentes razas, diferentes grupos étnicos, diferentes clases, civilización/naturaleza, cultura occidental/cultura del tercer mundo" (Dussel, 2001, pág. 69-70).

Una vez más se discute el principio de la diferencia colonial en la comprensión de la genealogía construida por las ciencias sociales modernas. Al respecto, Zulma Palermo (2005) plantea que la diferencia colonial es, fundamentalmente, diferencia 
Disputas de sentidos en las formas de habitar el mundo

Una propuesta conceptual para (re) pensar el hábitat en términos interculturales.

epistémica. Este planteamiento colabora en la construcción de formas que discutan el MCMC.

Palermo (2005) propone "apostar a la concreción de una epistemología de fronteras que persigue la 'diversidad' (Dussel), (...) una lógica distinta que haga posible la rearticulación de las historias (memorias) locales en una 'polifonía' mundial” (p. 95). Se trata de incorporar la pluriversalidad (Mignolo, 2005) de América Latina al caleidoscopio del mundo (Palermo, 2005). En consecuencia, la autora aboga por un distanciamiento de las críticas esencialistas y/o antieuropeas -sostenidas por la teoría de la dependencia- y sistematiza una perspectiva "crítica de los fundamentalismos, del colonialismo y de los nacionalismos eurocéntricos sobre el Tercer Mundo" (Palermo, 2005, p. 96). Para la autora salteña, esta es una de las cuestiones decisivas en su diferencia con el latinoamericanismo autonomista de los '60:

"atravesado también por un principio de totalización centrado en una monotópica internacionalidad latinoamericana hacia dentro de sí misma y desconociendo otras situaciones de dependencia similares en el mundo. Allí el encuentro con el deconstructivismo, aunque parcial, con el poscolonialismo y la subalternidad; no obstante, en conjunto, todos estos movimientos intelectuales consolidan lo que Santos ha dado en Ilamar una 'Epistemología del Sur'." (Palermo, 2005, p. 98)

Como dijimos antes, no desconocemos la existencia de algunos "ruidos" respecto de la perspectiva decolonial como parte de las epistemologías del Sur. Tenemos claro que para la decolonialidad la modernidad no es un proceso acabado, sino que está vigente. Mientras que Santos (2009) incorpora como epistemologías del sur a los estudios poscoloniales y algunos catalogados como posmodernos. Insistimos con la capacidad de alcance global de la perspectiva decolonial que, si bien tiene sus raíces en Latinoamérica, considera la existencia de otros actores y lugares "subalternizados" por el MCMC. No obstante, nos resulta más abarcativa la propuesta de Santos. Al respecto, el autor portugués dice "No se trata de diferenciar los varios colonialismos en el sentido de determinar los que fueron mejores y los que fueron peores, ya que todos fueron igualmente malos. Se trata, antes, de distinguir entre 


\section{Gonzalez Facundo}

diferentes prácticas de colonización para sintonizar mejor las prácticas que se les deben oponer" (Santos, 2009, p. 13).

La propuesta de Santos (2018) demanda comprender que es necesaria una visión telescópica del centro y una visión microscópica de todo lo rechazado por el centro para reproducir su credibilidad como tal. Así, el centro es el Norte Global donde los "otros" saberes, han sido producidos como no existentes o marginales, siendo radicalmente excluidos como válidos en el MCMC. Mientras el Sur Global es caracterizado por Santos (2009) como el momento de retorno de los humillados y subalternizados. El Sur es usado aquí como metáfora del sufrimiento humano, sistemáticamente causado por el colonialismo y el capitalismo:

“Es un Sur que también existe en el Norte global geográfico, el llamado Tercer Mundo interior de los países hegemónicos. A su vez, el Sur global geográfico contiene en sí mismo, no sólo el sufrimiento sistemático causado por el colonialismo y por el capitalismo, globales, sino también las prácticas locales de complicidad con aquéllos. Tales prácticas constituyen el Sur imperial (...) El sur de la Epistemología del Sur es el sur anti imperial" (Santos, 2009, p.12).

El intelectual nos propone comprender la dicotomía Norte-Sur a partir de una línea abisal, que legitima la hegemonía política del MCMC, mantenida a partir de las desigualdades del sistema mundial:

"La frontera constituye una metáfora, una frontera que, si por un lado puede legitimar la racionalidad dominante, por otro reconoce la existencia de subjetividades y sociabilidades alternativas que permiten la construcción de un nuevo paradigma basado en los principios de solidaridad y comunidad (...)" (Santos, 2018, p.26).

La composición de la dicotomía Norte-Sur y la disposición de las relaciones jerárquicas expresan la persistencia de las relaciones impuestas a partir del MCMC. Así, la Epistemología del Sur se presenta como una propuesta realista sin perder la dimensión utópica, para dilatar el presente y contraer el futuro. Santos (2009) dice al respecto que es necesaria la búsqueda de saberes y otras formas de validación para visibilizar las prácticas cognitivas de los grupos sociales que han sido históricamente victimizados, explotados y oprimidos por el colonialismo y el capitalismo globales. 
Disputas de sentidos en las formas de habitar el mundo

Una propuesta conceptual para (re) pensar el hábitat en términos interculturales.

La propuesta de Santos (2018) compone un aparato epistemológico que demanda, en términos del autor, el diseño de una postura epistemológica que contenga las experiencias y saberes relegados $-\mathrm{y} / \mathrm{o}$ aniquilados - por el MCMC. Concretamente, el autor entiende a las Epistemologías del Sur como:

“(...) un conjunto de indagaciones sobre la construcción y validación del conocimiento nacido en la lucha, de formas de saber desarrolladas por grupos y movimientos sociales como parte de su resistencia contra injusticias y opresiones sistemáticas causadas por el capitalismo, el colonialismo y el patriarcado." (Santos, 2018, p. 27)

\section{DE LO INEXISTENTE A LO EXISTENTE, CRUZANDO EL ABISMO}

El MCMC invisibiliza aquello que no se corresponde con lo moderno, lo científico, lo occidental. La racionalidad científica occidental, posicionada desde la ignorancia arrogante, asume que nada tiene que aprender del Sur Global (Santos, 2018). Este Pensamiento Abisal produce una línea abisal que estructura el pensamiento moderno eurocéntrico y nutre la configuración de las relaciones políticas y culturales excluyentes que sostienen el sistema - mundo colonial moderno.

Usando la metáfora planteada en el título (Cruzando el Abismo), partimos de tres conclusiones facilitadas por Santos (2009):

1- La experiencia social en todo el mundo es mucho más amplia y variada de lo que la tradición científica y filosófica occidental conoce y considera importante.

2- "De este desperdicio se nutren las ideas que proclaman que no hay alternativa, que la historia llegó a su fin, y otras semejantes" (Santos, 2009, p. 99)

3- Para hacer visibles las experiencias, iniciativas y movimientos alternativos hay que recurrir a una ciencia social otra, que no esconda o desacredite las alternativas. Se trata de un modelo diferente de racionalidad.

La Racionalidad "universal, europea, occidental", que sostiene el universalismo del MCMC, es caracterizada por Santos como una Razón Indolente constituida por cuatro razones diferentes: la impotente (aquella que no se ejerce porque piensa que nada se puede hacer contra una necesidad concebida como exterior a ella misma), la arrogante (no siente la necesidad de ejercerse porque considera incondicionalmente 


\section{Gonzalez Facundo}

libre, incluso de demostrar su libertad), metonómica (la única forma de racionalidad, no busca descubrir otras formas de racionalidad), y proléptica (que no tiende a juzgar el futuro, porque considera que lo sabe todo de él, y lo concibe como una superación lineal, automática e infinita del presente) (Santos, 2009).

Así, la razón metonímica propone un modo único de existir, produciendo la no existencia de lo que no cabe en su totalidad y en su tiempo lineal. Santos (2009) reconoce cinco procesos de producción de la no existencia, unidos como diferentes lógicas de la manifestación de esta monocultura racional: 1) Monocultura del saber (las ciencias modernas como única verdad. La no existencia asume aquí la forma de ignorancia o incultura); 2) Monocultura del tiempo lineal (según la cual la historia tiene sentido y dirección únicos y conocidos. La no existencia se produce declarando atrasado todo lo que, según la norma temporal, es asimétrico con relación a lo que es declarado avanzado); 3) Monocultura de la naturalización de la diferencia (lógica de la clasificación social que consiste en la distribución de las poblaciones por categorías, como la racial o sexual, que naturalizan jerarquías); 4) Lógica de escala dominante (la escala adoptada como primordial determina la irrelevancia de todas las otras escalas posibles. La no existencia es producida bajo la forma de lo particular (versus el universalismo abstracto) y lo local (versus la globalización neoliberal); 5) Monocultura de los criterios de productividad capitalista (en esta lógica el crecimiento económico es un objetivo racional incuestionable al igual que la idea de maximización de la productividad. La no existencia es producida bajo la forma de improductivo) .

La producción de estas formas de no existencia, de ausencias, "desemboca en la sustracción del mundo y en la contracción del presente y, por consiguiente, en el desperdicio de la experiencia" (Santos, 2009, p.112). Y la tarea de transformar lo inexistente en existente, lo imposible en posible, lo ausente en presente requiere de la construcción de un pensamiento posabisal que se centre en los fragmentos de la experiencia social no socializados por la totalidad metonímica. A esto, Boaventura de Sousa Santos (2009) denomina Sociología de las Ausencias: "La sociología de las ausencias intenta identificar el ámbito de esa sustracción y de esa contracción del 
Disputas de sentidos en las formas de habitar el mundo

Una propuesta conceptual para (re) pensar el hábitat en términos interculturales.

mundo para que esas experiencias producidas como ausentes sean liberadas de esas relaciones de producción y, por esa vía, se tomen presentes" (p. 112).

La sociología de las ausencias se ocupa de la razón metonímica (erigida como totalizadora ) cuestionando y visibilizando las formas de monocultura que producen ausencias. Aquí, Santos advierte que al ser las ciencias sociales hegemónicas producto del pensamiento abisal -asociado a la razón metonímica impuesta por el MCMC-, es necesario romper los esquemas tradicionales de la epistemología occidental y propone un pensamiento posabisal a partir de las premisas programáticas de la ecología de saberes (Santos, 2009).

Así, la Sociología de las Ausencias opera sustituyendo monocultura por Ecologías como “(...) práctica de agregación de la diversidad a través de la promoción de interacciones sustentables entre entidades parciales y heterogéneas" (Santos, 2009, p. 113). El autor propone, a partir de la confrontación de cada una de las lógicas de producción de monocultura, cinco ecologías :

1) Ecología de los Saberes: como práctica de exploración de concepciones alternativas a la monocultura del conocimiento. Parte de un principio de incompletud a partir del presupuesto de que la experiencia humana implica más que una forma de saber y de ignorancia.

2) Ecología de las Temporalidades: como propuesta alternativa a la concepción lineal del tiempo de la modernidad. Propone la idea de existencia de otras temporalidades apoyadas en una sapiencia multitemporal que permita la co-presencia de otras formas de percibir el tiempo.

3) Ecología de los Reconocimientos: en esta ocasión el autor cuestiona la lógica de clasificación social y para eso se apoya en la colonialidad del poder señalando cómo el MCMC identifica la diferencia con la desigualdad y se adosa el privilegio de determinar quién es igual y quien es inferior o diferente (consecuentemente inexistente). Esta Ecología propone reconocimientos mutuos y recíprocos.

4) Ecología de las Transescalas: como crítica a la lógica de monocultura de universalismo abstracto y de la escala global, Santos plantea una recuperación 


\section{Gonzalez Facundo}

simultánea de aspiraciones universales ocultas y de escalas locales/globales alternativas que no resultan de la globalización hegemónica.

5) La Ecología de la Productividad: consiste en la recuperación y valorización de los sistemas alternativos de producción, de las organizaciones económicas populares, de las cooperativas obreras, de las empresas auto-gestionadas, de la economía solidaria, etc. que el sistema capitalista oculta o desacredita (Santos, 2009).

Las premisas programáticas propuestas por el intelectual portugués tienen por objetivo revelar la diversidad y multiplicidad de las prácticas sociales expuestas en las experiencias de cada grupo. Además, pretende habilitar un vínculo de co-existencia sin pretensiones destructivas. Al respecto, Santos señala:

"Común a todas estas ecologías es la idea de que la realidad no puede ser reducida a lo que existe. Se trata de una versión ampliada del realismo, que incluye las realidades ausentes por la vía del silenciamiento, de la supresión y de la marginalización, esto es, las realidades que son activamente producidas como no existentes" (Santos, 2009, p. 125)

Finalmente, el ejercicio de la sociología de las ausencias implica una operación de confrontación de lo que Santos llama Imaginación Sociológica y que clasifica en Imaginación Epistemológica e Imaginación Democrática. Ambas poseen una dimensión deconstructiva (asociada a la crítica de las lógicas de monocultura: despensar, des-residualizar, des-racializar, des-localizar y des-producir) y una reconstructiva (constituida por las cinco ecologías).

Así, reconocemos lo potente de la propuesta de Santos para reconocer las formas de configuración del MCMC, que opera con vigencia -a través de sus diferentes facetas- pero innegablemente puesto en cuestión.

Esta potencia reside en la capacidad de hacer visibles componentes del MCMC que operan como dados, naturalizados a partir de la experiencia colonial y capitalista, y que constituyen una dimensión supra. Esta dimensión, que invisibiliza las experiencias, tiene un reflejo -en muchos casos resistencia- en lo que consideramos 
Disputas de sentidos en las formas de habitar el mundo

Una propuesta conceptual para (re) pensar el hábitat en términos interculturales.

una dimensión infra hábitat, allí donde habitan, residen, se reconvierten esas "ausencias" que se configuran en presencias latentes.

\section{DE LA DILATACIÓN DEL PRESENTE Y LA EXPANSIÓN DEL FUTURO}

Si la sociología de las ausencias nos propone una forma, a la vez realista y utópica, de expandir el presente que el MCMC impone, la crítica al componente proléptico de la razón indolente expone la necesidad de contraer el futuro evidenciando las condiciones de la monocultura del tiempo lineal.

Santos (2009) señala que el universalismo impuso un sentido y una dirección a la historia, otorgado por la idea de un progreso que no tiene límites. Así, si el futuro está proyectado en un orden y dirección irreversible, es un tiempo homogéneo y vacío, destinado a convertirse en pasado: "Un futuro concebido de ese modo no tiene como ser pensado, y en esto se fundamenta la indolencia de la razón proléptica" (Santos, 2009, p. 126).

Contraer el futuro significa quitarle el componente de infinito, hacerlo escaso y convertirlo en objeto de cuidado. Para Santos (2009) el futuro no tiene otro sentido ni dirección más que la que resulta de ese cuidado: "Contraer el futuro consiste en eliminar o, por lo menos, atenuar la discrepancia entre la concepción del futuro de la sociedad y la concepción de futuro de los individuos" (Santos, 2009, p. 129).

El autor propone un doble juego, ya que plantea que la contracción del futuro contribuye a la dilatación del presente, atando la propuesta de sociología de las ausencias a lo que denomina una sociología de las emergencias criticando el carácter finito del futuro y:

"el hecho de que dependa de la gestión y cuidado de los individuos hace que, en vez de estar condenado a ser pasado, se transforme en un factor de ampliación del presente ya que es en el presente que se cuida el futuro" (Santos, 2009, p.126-127).

Apoyándose en diferentes tradiciones culturales y filosóficas, Santos señala que la sociología de las emergencias consiste en:

“(...) sustituir el vacío del futuro según el tiempo lineal (un vacío que tanto es todo como nada) por un futuro de posibilidades plurales y concretas, 


\section{Gonzalez Facundo}

simultáneamente, utópicas y realistas, que se va construyendo en el presente a partir de las actividades de cuidado." (2009, p. 127)

Se destacan los aportes de Ernest Bloch (1995) y su concepto de "Todavía-No" (Noch Nicht) como precedentes de la sociología de las emergencias. Santos hace hincapié, a partir de la crítica de Bloch a la filosofía occidental, en la concepción mecánica de materia y la afirmación de la capacidad de pensar y actuar en el mundo:

“De las tres categorías modales de la existencia -la realidad, la necesidad y la posibilidad (Bloch, 1995)- la razón indolente se centró en las dos primeras y descuidó completamente la tercera" (Santos, 2009, p. 128).

En ese sentido, tanto Santos como Bloch señalan a la filosofía occidental como estática y en una crítica filosófica a Hegel, lo consideran responsable del descuido filosófico de lo posible. Sobre esto y en relación a la propuesta de la sociología de las emergencias, Santos dice:

"La sociología de las emergencias actúa tanto sobre las posibilidades (potencialidad) como sobre las capacidades (potencia). Lo Todavía No tiene sentido (en cuanto posibilidad), pero no tiene dirección, ya que tanto puede acabar en esperanza como desastre" (2009, p. 129).

Así, la sociología de las emergencias viene a sustituir la idea mecánica de determinación y de progreso por la idea axiológica del cuidado (Santos, 2009). De este modo, mientras la sociología de las ausencias se apoya en una axiología del cuidado a partir de la puesta en práctica en relación a las alternativas, la sociología de las emergencias lo hace en relación con las alternativas posibles. (Santos, 2009)

La propuesta de Santos es particular ya que su "objetividad" depende de la calidad de su dimensión subjetiva:

"El elemento subjetivo de la sociología de las ausencias es la conciencia cosmopolita y el inconformismo ante el desperdicio de la experiencia. El elemento subjetivo de la sociología de las emergencias es la conciencia anticipadora y el inconformismo ante una carencia cuya satisfacción está en el horizonte de las posibilidades". (2009, p. 130) 
Disputas de sentidos en las formas de habitar el mundo

Una propuesta conceptual para (re) pensar el hábitat en términos interculturales.

En el marco la propuesta de Santos, cobra central interés el papel del intelectual, a quien le asigna un rol de facilitador, alejado del clásico derecho de tener un conocimiento de vanguardia. El autor propone un intelectual en territorio, acompañando los procesos de lucha, conociendo experiencias, compartiendo ideas y aprendiendo a hablar en términos científicos sin terminología científica, haciéndolo inteligible. A esto llama Intelectual de Retaguardia, y lo caracteriza como:

"O sea el rol es ir con los movimientos, con las fuerzas que están intentando resistir. Con ellas, facilitando, trayendo la experiencia científica que tenemos para ayudar en la lucha, pero muchas veces ayudando a los que van más despacio, la gente que está a punto de desistir en la lucha. Los que están adelante, los protagonistas de los movimientos son distintos. Trabajo con los voceros de las revueltas de indignación, que son movimientos diferentes porque es otra manera de estar en el mundo de la rebelión" (Santos, 2014, p. 78).

Las Epistemologías del Sur, como alternativas críticas y propositivas del MCMC no pretenden anularlo, sino que cuestionan su ejercicio monopólico de asignación y disciplinamiento de condiciones de existencia, de producción de conocimientos y de subjetividad, de supresión de la diferencia, etc.

DE LAS AUSENCIAS Y DE LAS EMERGENCIAS AL TRABAJO DE TRADUCCIÓN INTERCULTURAL

Las Epistemologías del Sur se componen de dos procedimientos: la ecología de saberes -explicada anteriormente- y la traducción intercultural. Resulta, entonces, conveniente para el desarrollo de este apartado, sistematizar algunos enfoques sobre interculturalidad, dejando de lado -aunque no desconociendo- su conceptualización en otras regiones o territorios del mundo.

De un tiempo a esta parte, la interculturalidad forma parte del discurso y de las políticas públicas regionales: "el discurso intercultural (...) fue ganando espacio en diferentes ámbitos, convirtiéndose en una suerte de lugar común para reflexionar acerca de los vínculos entre los pueblos indígenas, las trayectorias formativas y las instituciones de educación formal" (Ossola, 2016, p. 62). Sin embargo, advertimos que, de ninguna manera el diseño y aplicación de las políticas públicas 


\section{Gonzalez Facundo}

"interculturales" se realiza desde una perspectiva crítica de la interculturalidad (Rodríguez, 2020).

La perspectiva de "interculturalidad crítica" de Catherine Walsh (2010) define a la interculturalidad como "una herramienta, como un proceso y proyecto que se construye desde la gente -y como demanda de la subalternidad-, en contraste a la funcional, que se ejerce desde arriba. Apuntala y requiere la transformación de las estructuras, instituciones y relaciones sociales, y la construcción de condiciones de estar, ser, pensar, conocer, aprender, sentir y vivir distintas" (Walsh, 2010, p. 78). Además, aclara que esta interculturalidad no es algo que "existe", y en línea con Santos, menciona la existencia de experiencias con este horizonte.

Así pues, la pretendida universalidad -visibilizada en las cinco monoculturaresulta inconciliable con el concepto de interculturalidad, en tanto este último refiere no sólo a la co-existencia de múltiples culturas -multiculturalidad-, sino a la posibilidad y necesidad de un diálogo, una interacción entre esas culturas, basado en la aceptación mutua, sin jerarquizaciones y fortaleciendo la diversidad, sostenida en lo que Santos denomina Ecologías. La multiculturalidad, la existencia de diversas culturas, resulta indudable y por ello apelamos a una perspectiva intercultural (que para nosotros es a la vez decolonial), en oposición MCMC que produce como no existente a muchas culturas en pos de jerarquizar una única como válida para todos. La interculturalidad, más que un simple concepto de interrelación, "señala y significa procesos de construcción de conocimientos 'otros', de una práctica política 'otra', de un poder social 'otro', y de una sociedad 'otra', formas distintas de pensar y actuar con relación a y en contra de la modernidad/colonialidad" (Walsh, 2014, p. 17)

En la interculturalidad no es aplicable el auditorio universal de Toulmin, porque en él la única voz que se escucha es la del argumentador, en cambio deben escucharse todas las voces, algunas de las cuales no pueden ni tienen por qué asumir una conciencia de racionalidad occidental, ni de universalidad conceptual, ni justificar el motivo por el que se sienten fuera de esa problemática. Aquí, se evidencia la limitación de las lógicas de producción de monocultura (Rodríguez, 2020). 
Disputas de sentidos en las formas de habitar el mundo

Una propuesta conceptual para (re) pensar el hábitat en términos interculturales.

En la misma línea, ponemos en cuestión algunos conceptos, como por ejemplo lo expresado por Habermas acerca de que "la universalidad se impone por encima del potencial relativismo cultural" (Rodríguez, 2010, p. 231). De ninguna manera puede equipararse el relativismo cultural mencionado por Habermas con la interculturalidad como la venimos definiendo, ya que el concepto de relativismo refiere a la misma mirada universalista que se posa magnánimamente sobre el Otro para tratar de comprenderlo, asimilarlo o -como última instancia- tolerarlo. Esta no deja de ser la mirada eurocéntrica al plantear un relativismo cultural en lugar de un relativismo de la universalidad.

La interculturalidad como parte de las Epistemologías del Sur cuestionan y tensionan todo el aparato disciplinador del MCMC. Así, disputan los sentidos sobre verdad, validez y rectitud -entre otros- definidos como invariantes de la racionalidad. La forma en que el ser humano se sitúa en el mundo no es una invariante. Para el pensamiento metafísico occidental es fundamental "ser en el mundo". Por ejemplo, para los pueblos indígenas que habitan la región salteña no importa el ser, sino, como señala Kusch "estar en el mundo". No hay -a nuestro entender- una racionalidad que circule por sendas homogéneas en la interpretación del sentido y nada hay que pueda llamarse "verdad", ni "más válido", ni "más recto", en una visión que en otra. Sólo hay diferencia. La racionalidad - entonces- no puede ser forma de realizar la interculturalidad.

Santos (2018) plantea el trabajo de traducción intercultural para enfrentar a la diversidad y el conflicto en ausencia de una teoría general centrada en occidente y una política centralizada e impuesta. Así, el autor conceptualiza a la traducción intercultural, en el plano político, como:

“(...) un imperativo dictado por la necesidad de ampliar la articulación política más allá de los confines de un determinado lugar o cultura dada. (...) y consiste en buscar intereses isomorfos y supuestos subyacentes entre culturas, en identificar diferencias y similitudes, y en desarrollar siempre que corresponda, nuevas formas hibridas de comprensión e intercomunicación culturales que puedan servir para promover interacciones y fortalecer alianzas entre los movimientos sociales que, en 


\section{Gonzalez Facundo}

distintos contextos, luchan contra el capitalismo, el colonialismo, y el patriarcado (...)" (Santos, 2018, p. 267-268).

A su vez, Santos (2018) apoya su idea de traducción intercultural en la categoría de "filosofía viva" (filología viviente) de Gramsci (1975), caracterizándola como un “(...) proceso vivo de complejas interacciones entre artefactos heterogéneos, lingüísticos y no lingüísticos (...)” (p. 271) que van más allá de los textos y discursos, centrándose en las condiciones sociales y políticas. Para Santos, resulta central incorporar como elemento constitutivo del trabajo de traducción, la preocupación por el entendimiento y la comprensión de la diferencia -excediendo el contexto académico-.

Además, el pensador portugués revisa el concepto de traductibilidad de Walter Benjamin (1999) y toma la necesidad de reconocimiento de la diferencia y la motivación para ocuparse de ella como forma de comprensión de los procesos de construcción de hegemonía. Claramente Santos, se distancia de la traductibilidad como la acción necesaria para la apropiación cultural o existencial, o ese movimiento de desplazamiento de extrañeza a familiaridad.

Otros argumentos que sostienen el concepto de traducción intercultural están relacionados la necesidad de reducir -hasta eliminar si fuera posible- las asimetrías que están presentes en el trabajo de traducción. El autor está especialmente preocupado por la traducción como proyecto político para el empoderamiento mutuo y a los cambios que experimenta la identidad de los traductores. Santos (2018) advierte que compartir significados incluye compartir pasiones, sentimientos $y$ emociones:

"Tanto el marcar como el desmarcar las diferencias se inscriben en el proceso de intersubjetivación e interidentificación. A medida que cambian los sujetos de la traducción, cambian las polaridades que los separan. La reformulación y la interpretación son traducción en acción" (p. 278).

También resulta importante destacar la necesidad reconocer el phatos de la traducción intercultural. Es decir, ¿Qué motivaciones sostienen la traducción intercultural? Retomando la idea de "Filosofía Viva" de Gramsci, Santos (2018) señala 
Disputas de sentidos en las formas de habitar el mundo

Una propuesta conceptual para (re) pensar el hábitat en términos interculturales.

que la traducción intercultural implica un esfuerzo colectivo de trabajar con passionalità:

"Este concepto [passionalità] es de suma importancia porque subraya los sentimientos que encarnan el acto de participar en los significados y afectos, y compartirlos, mientras se desarrolla el proceso de traducción" (p.278).

Santos propone la constitución de un "espacio intermedio" que construya un otro y un nosotros equívoco, sin pretensiones de desacreditar las representaciones hegemónicas ni las contra-hegemónicas, sino la de construir eso que Viveiros de Castro (2004) llama espacio del equívoco:

"Traducir es enfatizar o potenciar el equívoco, es decir, abrir y ampliar el espacio imaginado para no existir entre lenguas conceptuales en contacto, un espacio que precisamente el equívoco ocultaba. El equívoco no es lo que impide la relación, sino lo que la cimienta e impulsa: una diferencia en perspectiva (...)" (Viveiros de Castro, 2004, p. 10).

Apoyando en estos aportes, pero pretendiendo ampliar los alcances de su propuesta, Santos (2018) sostiene a la traducción como una zona de contacto en la siguiente clave:

“(...) las zonas de contacto son zonas en las que ideas normativas, saberes, formas de poder, universos simbólicos y agencias opuestos se encuentran en condiciones normalmente desiguales, y se oponen, rechazan, imitan, traducen y subvierten mutuamente, dando así origen a constelaciones culturales híbridas en que la desigualdad de los intercambios puede ser reforzada o reducida." (p. 276)

El autor asegura que las zonas de contacto generadas por la traducción intercultural son "espacio-tiempos de mediación y negociación en los que la desigualdad de las relaciones translacionales son el principal factor condicionante (...)" (2018, p. 276). Alejado de una posición ingenua, Santos (2018) apunta a la necesidad de reducir esa desigualdad advirtiendo que las constelaciones culturales que emergen de los procesos de traducción pueden constituirse de forma más menos estables, provisionales y reversibles. 


\section{Gonzalez Facundo}

Así, la traducción intercultural pone en cuestión las dicotomías entre saberes y se erige como una traducción inter-política, un procedimiento que fomenta la política inter-movimiento y una herramienta que pretende reducir la lógica de inconmensurabilidad entre grupos sociales que luchan contra los designios del MCMC en todo el mundo, cuando los obstáculos sean diferencias culturales o ininteligibilidad mutua (Santos, 2018).

LA COMUNICACIÓN COMO ESCENARIO DEL TRABAJO DE TRADUCCIÓN INTERCULTURAL

Resulta relevante realizar una vinculación más profunda entre el enfoque de Interculturalidad y las Epistemologías del Sur para pensar la Comunicación como soporte del trabajo de traducción intercultural. En este sentido, Anibal Quijano (1992), al reclamar la necesidad de reconocer la colonialidad del saber, propone construir una nueva Comunicación, una inter-cultural, que se apoye en:

“(...) un intercambio de experiencias y de significaciones, como la base de otra racionalidad, que pueda pretender, con legitimidad, a alguna universalidad. Pues nada menos racional, finalmente, que la pretensión de que la específica cosmovisión de una etnia en particular sea impuesta como la racionalidad universal (...) porque eso en verdad es pretender para un provincianismo el título de universalidad." (Quijano, 1989, p.447).

Al referirse al giro decolonial, Walter Mignolo (2007) plantea que la perspectiva significa una apertura hacia la libertad de pensamiento y hacia formas "otras" de vida.

Vista desde esta perspectiva, pareciera asignársele a la Comunicación un principio de "comunicar la diferencia" , a partir de lo que más arriba señalábamos como marque y desmarque de los procesos de subjetividad e inter-identificación, como escenario de las zonas de contacto que constituyen el trabajo de traducción intercultural. Pero sería ingenuo caer en la clásica perspectiva de Comunicación como medio o como soporte, largamente cuestionada. Por eso elegimos entender la Comunicación, también, como un diálogo de saberes que abona a la comprensión de 
Disputas de sentidos en las formas de habitar el mundo

Una propuesta conceptual para (re) pensar el hábitat en términos interculturales.

los escenarios donde trabajar la pretendida traducción intercultural. Para esto es clave construir su conceptualización en términos tanto teóricos como empíricos.

Así, la Comunicación, como campo de conocimiento, sin una tradición disciplinar enraizada y delimitada, es más bien percibida como una ventaja en el marco del enfoque de trabajo que aquí proponemos. Al respecto, Raúl Fuentes Navarro (1998) señala que la Comunicación "apuesta por la superación de las fronteras existentes entre las disciplinas, por la integración metodológica (...) por el abandono del afán de disciplinar su estudio; esto es, por la negación de una posibilidad de una comunicología" (p. 16). Esta posición se contrapone con la opinión de otros referentes del campo, como Jesús Galindo (2003), quien plantea desarrollar una “Comunicología posible mediante la articulación, en una matriz, de las vertientes analíticas de la difusión masiva, la terapia interpersonal y los estudios culturales “(p. 10).

Sobre el estatuto epistemológico de la Comunicación, León Duarte (2006) ha señalado que la perspectiva sociocultural se constituye en la visión predominante de la investigación académica, dentro de un contexto de prácticas de investigación orientadas a las ciencias sociales, y con fuerte demanda de definición precisa del estatuto disciplinario. De modo tal que el estatuto disciplinar de las ciencias de la Comunicación evolucionó hacia la superación de los límites entre las especialidades de los campos de "conocimientos universales". Así pues, entendemos a la Comunicación como un campo transhistórico, sociocultural y complejo, multidimensional, centrado en la subjetividad y en los procesos de producción/reconocimiento de sentidos y significaciones. En consecuencia, el pensamiento transdisciplinar representa una perspectiva relativamente reciente, originada en el proceso histórico de la globalización (Moyano, 2016, p. 24).

Torrico Villanueva (2004) señala que el objeto de estudio de la Comunicación:

“(...) es el proceso, circulación mediada, intercambio desigual, intelección, y uso de significaciones y sentidos culturalmente situados, que es algo de naturaleza socialmente estructural e inseparable -para fines teóricos e investigativos- de las otras dimensiones analíticas de la vida social que se estudian". (p. 31) 


\section{Gonzalez Facundo}

Este autor advierte que la definición antes señalada responde al objeto teórico de la Comunicación. En cambio, serán objetos concretos los Procesos Comunicacionales reales sometidos a observación y estudio. La utilización de este concepto pretende guardar coherencia con una concepción de la Comunicación que se apoya, sobre todo, en las relaciones y en las interacciones entre los sujetos que son actores de esta (Uranga, 2017). Concretamente, nos referimos a las prácticas de comunicación que se verifican y pueden ser reconocidas en el espacio social. Es decir, a situaciones de comunicación protagonizadas por actores, individuales o colectivos, en permanente dinamismo y situados en proyectos, en organizaciones, en instituciones. Los procesos comunicacionales hacen referencia a los actores, a espacios de necesidades y demandas comunicacionales vinculadas con las prácticas sociales (Uranga, 2017).

De esta forma, la multidimensionalidad, característica del objeto de estudio teórico de la Comunicación, tiene gran consenso en el campo; representado en el cruce de esa línea abisal que la ciencia tradicional no reconoce como existente. Esto se debe a que su cualidad estructural pretende atravesar diversos ámbitos de la existencia y las realidades sociales, de forma transversal y flexible.

En el plano local, latinoamericano, reconocemos como aporte inspirador de la perspectiva comunicacional aquí adoptada a la Comunicología de Liberación propuesta por el boliviano Luis Ramiro Beltrán (1976). Esta puede ser considerada entre las fuentes del pensamiento decolonial, junto a otras elaboraciones del anticolonialismo latinoamericano de entonces, criticas de las promesas de modernización.

La Comunicación, pensada desde las epistemologías del sur, es blanco de críticas por las teorías hegemónicas del siglo XX, como la Comunicación para el Desarrollo -vinculada a la idea moderna de progreso-, impregnada de supuestos foráneos surgidos después de la segunda Guerra Mundial y que, si bien pretendió un aggiornamiento, nunca modificó su matriz colonial moderna capitalista (Torrico Villanueva E., 2013).

La Comunicación, heredera de la propuesta de Beltrán, invita a investigar, entender y gestionar -en los términos planteados por Santos- las zonas de contacto 
Disputas de sentidos en las formas de habitar el mundo

Una propuesta conceptual para (re) pensar el hábitat en términos interculturales.

desde una perspectiva que rompa con la lógica de la moderno, colonial, capitalista y patriarcal. En consecuencia, que recomponga los instrumentos del conocimiento y que esté orientada por el acceso, el diálogo y la participación democráticos, inscribiéndose en el horizonte político de las Epistemologías del Sur.

Así, y de forma subsidiaria, adosamos al concepto de Comunicación el de Diálogo de Saberes propuesta por Fals- Borda (1987) vinculando la dimensión política del objeto real a estudiar. Lejos de la mirada crédula de un vínculo simétrico "entre culturas", el diálogo de saberes promueve un compromiso profundo por el mejoramiento de las condiciones de vida de los pueblos y grupos excluidos a partir de buscar articulaciones entre sectores tan distantes como la intelectualidad y los sectores populares. Fals- Borda (1987) sienta las bases para "una forma de investigar por encima de las diferencias culturales y regionales" (p. 161), reiterando el empleo humanista de la ciencia y condenando el uso totalitario y dogmático del conocimiento. Destaca, así, el sentido político del conocimiento y la relación de éste con la cultura y el poder.

COMUNICAR LA DIFERENCIA, HABITAR LA EXPERIENCIA: HÁBITAT EN ZONAS DE CONTACTO ATRAVESADOS POR DIMENSIONES INFRA Y SUPRA

En la mayoría de los casos, hábitat, prefigura formas de habitar que se corresponden con el MCMC. En este sentido, pretendemos reconfigurar la conceptualización e incluir otras relaciones entre habitar, espacio social y territorio. Relaciones invisibilizadas, subalternizadas y despojadas de legitimidad.

Las formas en que se habita se expresan a través de cosmovisiones de hábitat diferentes, constituidas por dimensiones de la vida social muy importantes: el sentido sobre el propio hábitat, el vínculo con el ambiente que lo constituye, el estatuto simbólico de los espacios que se habitan, la relación con la materialidad que se habita, la organización social comunitaria, etc.

Así, entendiendo al hábitat como un tipo de territorialidad, construida a partir de un tipo específico de experiencia siempre colectiva, es posible indagar sobre los procesos de construcción del territorio y la experiencia de habitar (lo) de las comunidades que forman parte del mismo. 


\section{Gonzalez Facundo}

Con ese horizonte, proponemos una definición de hábitat como una territorialidad, marcada por la experiencia de habitar, entendido desde el ejercicio de producción y reproducción de sentidos que cristalizan dimensiones supra e infra hábitat. Así, el hábitat se configura en este trabajo como un objeto doblemente descentrado, donde hallamos aspectos infra y supra hábitat.

Infra y Supra hábitat tienen la intención de ayudar a (re) pensar (o tratar de clasificar para el análisis) dimensiones y componentes que -si bien se atraviesan, complementan y yuxtaponen- son posibles de reconocer en la producción de hábitat, sin dejar de considerar sus vinculaciones intrínsecas. Es decir, concebimos al hábitat como una categoría doblemente descentrada, para entender su configuración: al descentrarla se des-esencializa y se habilita la mirada a una serie de fenómenos que van a componer lo que particularmente entiende una comunidad como hábitat en un determinado territorio.

Entonces, pensamos la serie de elementos supra como todas las formas de cristalización del MCMC, observables en la (re)producción de sentidos impuestos por la razón indolente como un modo único de, produciendo la no existencia de lo que no cabe en su totalidad y en su tiempo lineal.

Por su parte, lo infra permite acceder -desde la propuesta de ecologías y traducción intercultural - a formas de evocación de la memoria, (re)asignación de sentidos a las tecnologías de hábitat y continuidad de saberes y prácticas invisibles que también operan en las formas de habitar.

Los proyectos de extensión/investigación con poblaciones indígenas de la puna y el chacho salteños, funcionaron como mediadores para adentrarnos en las experiencias de producción de hábitats de las comunidades Kolla de Hurcuro y Wichí de El Cocal y sus expectativas. Estas comunidades forman parte de pueblos diferentes, que habitan regiones naturales diversas, sus culturas se asientan en prácticas disímiles y fueron objeto de procesos de colonización en temporalidades diferentes. Estas características, que hacen imposible comparar formas de producción de hábitat, permiten reconocer signos de resistencias, disputas, emulaciones y adaptaciones, cuyo abordaje resulta importante para una mejor comprensión de la manera en que hoy 
Disputas de sentidos en las formas de habitar el mundo

Una propuesta conceptual para (re) pensar el hábitat en términos interculturales.

producen sus hábitats. Este proceso es el que nos permitió problematizar las nociones de hábitat con las que nos acercamos inicialmente al campo, e intentar identificar aquello que decidimos denominar supra e infrahábitat.

Es posible reconocer elementos de cada uno de estos niveles a partir de la operación desde la sociología de las ausencias en el campo de las experiencias sociales y desde la sociología de las emergencias en el campo de las expectativas sociales.

Se subraya el carácter no dado del hábitat y más aun de la experiencia de habitar y el enfoque comunicacional de producción de sentidos nos permite ingresar desde una perspectiva privilegiada a ese proceso de construcción de territorio/hábitat.

Entendemos que la clave comunicacional y de sentidos es un punto privilegiado a la hora de pensar la gestión de proyectos que intervengan el hábitat de una comunidad, y si la experiencia de hábitat consiste en un trabajo con indígenas es necesario adoptar una posición consistente con los supuestos que hasta aquí hemos asumido. Es decir, incluir elementos que atiendan a la diversidad cultural, promoviendo la interculturalidad crítica, desde el trabajo de traducción intercultural apoyado en una sociología que represente ausencias y emergencias situadas. 


\section{Gonzalez Facundo}

\section{Bibliografía}

Aguirre, L. y Burmester, M. (2014) “Aula abierta en la gestión del hábitat”. I Congreso Nacional de Epistemología Crítica en el campo del hábitat. Córdoba: CIECS.

Beltrán, L. R. (1976) “Alien Premises, Objects and Methods in Latin American Communication Research". Communication Research an International Quarterly. Michigan, USA. Vol. 3, No. 2, pp. 107-134.

Benjamin, W. (2002) "The Task of Translator". En Selected Writings Vol. 1. P. 253-263. Cambridge: Belknap Press.

Bhabha, Homi K., The location of culture Editorial: London; New York: Routledge, 1994.

Bloch, E. (1995) “The Principle of Hope". Cambridge: MIT Press

Brutto, N. (2013) “¿Cómo hacemos ciudad? Análisis del proceso de urbanización del barrio Presidente Perón a la luz de la teoría del riesgo". $1^{\circ}$ Jornada de Investigadores en Formación. Buenos Aires.

Castorina, J. y Carretero M. (2012) “Desarrollo cognitivo y educación. Procesos del conocimiento y contenidos específicos". Buenos Aires: Paidós.

Ceballos Guerra, J. C. (2015). “Para la Intervención en el hábitat la comunicación: acción social”. BDIGITAL, pp. 107-116

Cejas, N. (2013) “Procesos Comunicacionales en Prácticas de Co- Construcción del Conocimiento." Córdoba: CEA-UNC.

Di Virgilio, M. (2006) “¿Existen oportunidades para la creación de valor publico durante la implementación de los programas sociales? La implementación del ProMeBa en el conurbano bonaerense (Argentina 2002-2003)". Buenos Aires: Universidad Nacional de General Sarmiento.

Di Virgilio, M. y Rodríguez, M. (2009) “Idas y vueltas: el derrotero de las políticas descentralizadas de producción de vivienda social en las principales áreas metropolitanas de Argentina". Ecuador Debate, 76, pp. 75-92. 
Disputas de sentidos en las formas de habitar el mundo

Una propuesta conceptual para (re) pensar el hábitat en términos interculturales.

Diez, M. L. (2004) "Reflexiones en torno a la interculturalidad". Cuadernos de Antropología social (19), 191-213

Dussel, E. (1992) "1492: el encubrimiento del otro: hacia el origen del mito de la modernidad". Madrid: Editorial Nueva Utopía.

Dussel, E. (1999) Ética de la Liberación en la edad de la globalización y de la exclusión. Madrid: Editorial Trotta.

Dussel, E. (2000). "Europa, modernidad y eurocentrismo". En La colonialidad del saber: eurocentrismo y ciencias sociales. Perspectivas (págs. 24-33). Buenos Aires: CLACSO.

Dussel, E. (2001) “Hacia una filosofía política crítica”. Bilbao: Declée de Brouwer. Recuperado de: http://enriquedussel.com/txt/Textos_Libros/53.Hacia_filosofia_politica_critica.pdf

Fals-Borda, O. (1987) “Ciencia propia y colonialismo intelectual. Los nuevos rumbos". Bogotá: Carlos Valencia Editores.

Fernandez Wagner, R.; Varela, O.; Silva, M.. (2004) “La complejidad ausente en los programas de intervención socioespacial inscriptos en el paradigma de la reducción de la pobreza. El caso del ProMeBa en el Gran Buenos Aires". II Congreso Nacional de Políticas Públicas Sociales. Mendoza.

Fontenla, M. (2008) “¿Qué es el Patriarcado?”, en Diccionario de estudios de género y feminismos. Buenos Aires: Biblios

Fuentes Navarro, R. (1998) “La Emergencia de un campo académico: continuidad utópica y estructuración científica de la investigación en comunicación en Mexico". Guadalajara: ITESO.

Galindo, J. (2003) “Notas para una comunicología posible. Elementos para una matriz y un programa de configuración conceptual-teórica”. Hipertextos Revista electrónica del ITESM de Monterrey. Número 7. Agosto-diciembre.

González, F. y Chevez, P. (2016) “Política de Hábitat en la Provincia de Chubut. Construcción de Viviendas Sociales Bioclimáticas: Interacción entre actores, tecnologías y dinámicas sociopolítica"s. Revista AVERMA 45, 1-22. 


\section{Gonzalez Facundo}

González, F. (2019) “Estrategias de Hábitat en Salta: el caso del Programa de Mejoramiento Barrial (ProMeBa) 2015-2016" (Tesis de Maestría). Universidad Nacional de Quilmes. Bernal, Argentina.

González, F. y Rodríguez N. (2019) “Teoría Decolonial y estudios sobre Hábitat: construcción de un soporte epistemológico desde el enfoque de Comunicación e Interculturalidad". Revista Question, vol.1. La Plata

Gonzalez, Facundo (2020). Producción y circulación de sentidos en la configuración de las dimensiones supra e infra hábitat. Experiencias de producción de hábitat en la Puna y en el Chaco salteños a partir de proyectos de extensión con la comunidad Kolla de Hurcuro y el pueblo Wichí de El Cocal (Salta, 2017-2018) (Tesis de Doctorado). Universidad Nacional de Córdoba. Córdoba, Argentina.

Gramsci, A. (1975) "Quaderni de carcere”. Torino: Einaudi

Gudynas, E. (2011) “Buen Vivir: Germinando alternativas al desarrollo. América Latina en Movimiento". Publicación Internacional de la Agencia Latinoamericana de Información (ALAI). Separata: Destaques del Foro Social Mundial, 1-24.

Hardoy, J.; Sierra,G.; Ledesma,G.; Ledesma, L.; García, C. (2010) “Aprendiendo de los jóvenes y de nuestra experiencia en el barrio San Jorge". Ambiente y Urbanización, 125-146.

Insaurralde, A. (2007) “Capacidades comunitaria para el desarrollo: aportes de un programa social. El caso del ProMeBa". Buenos Aires: Universidad Nacional de San Martin.

Instituto Nacional de Estadísticas y Censos (INDEC) (2018) Encuesta Permanente de Hogares. República Argentina.

Jonsson, S. (2010). "La ideología del universalismo". NRL(63), 111-122.

Lander, E. (2000) “La colonialidad del saber: eurocentrismo y ciencias sociales. Perspectivas Latinoamericanas". Buenos Aires: CLACSO.

Lefebvre, H. (2013) “La producción del espacio”. Madrid: Capitán Swing

Leon Duarte, G. (2006). "Sobre la institucionalización del campo académico de la Comunicación en América Latina. Una aproximación a las características estructurales de la investigación latinoamericana en comunicación". Barcelona: Universidad Autónoma de Barcelona. 
Disputas de sentidos en las formas de habitar el mundo

Una propuesta conceptual para (re) pensar el hábitat en términos interculturales.

Llanos-Hernández, L. (2010) “El concepto de Territorio y la investigación en las Ciencias Sociales". Agricultura, sociedad y desarrollo, 7(3), 207-220.

Maldonado-Torres, N. (2007) "Sobre la colonialidad del ser: contribuciones al desarrollo de un concepto", en Castro-Gómez, S. y Grosfoguel, R. (eds.) El giro decolonial. Reflexiones para una diversidad epistémica más allá del capitalismo global. Bogotá, lesco-PensarSiglo del Hombre Editores, pp.127-167.

Marengo, C.; Elorza, A. L. (2010) “Calidad de vida y políticas de hábitat. Programa de mejoramiento barrial en Córdoba, Argentina. Caso de estudio: Barrio Malvinas Argentinas". Bitácora Urbano Territorial, 79-94.

Mignolo, W. (2003) “Un paradigma otro: colonialidad global, pensamiento fronterizo y cosmopolitismo crítico". En Mignolo, W. Historias locales/diseños globales. Colonialidad, conocimientos subalternos y pensamiento fronterizo. Madrid: AKAL

Mignolo, W. (2005) “La idea de América Latina. La herida colonial y la opción decolonial”. Barcelona: Gedisa

Mignolo, W. (2007) “El pensamiento decolonial: desprendimiento y apertura”. En CastroGómez, S y Grosfoguel, R. (comp.) El giro decolonial: reflexiones para una diversidad epistémica más allá del capitalismo global. Bogotá: Siglo del Hombre Editores, Universidad Central, Instituto de Estudios Sociales Contemporáneos y Pontificia Universidad Javeriana, Instituto Pensar.

Mignolo, W. (2016) “La colonialidad a lo largo y a lo ancho: el hemisferio occidental en el horizonte colonial de la modernidad". En Lander, E. (Comp.) La colonialidad del saber: eurocentrismo y ciencias sociales. Perspectivas latinoamericanas. Buenos Aires: CICCUS.

Miranda Gassull, V. (2016) El hábitat popular. Algunos aportes teóricos de la realidad habitacional de sectores desposeídos. Territorios, [S.I.], n. 36. doi: http://dx.doi.org/10.12804/revistas.urosario.edu.co/territorios/a.4440.

Moyano, R. (2016) “Procesos de Estructuración de las prácticas teórico-metodológicas de la investigación académica de América Latina. ALAICS y FELAFACS (200-2010)”. La Plata: Tesis Doctoral. 


\section{Gonzalez Facundo}

Nietzsche, Friedrich (1973): "Sobre verdad y mentira en sentido extramoral". En Revista Discurso y Realidad" Vol. II, №2.

ONU HABITAT (2018) Obtenido de www.onuhabitat.org.unchs/spanisch

ONU HABITAT (2020) Obtenido de www.onuhabitat.org.unchs/spanisch

Ossola, M. M. (2016). “Pueblos indígenas y educación superior en la Argentina: debates emergentes". Revista del Cisen Tramas/Maepova, 4 (1), 57-77.

Palermo, Zulma (2005) “Desde la otra orilla. Pensamiento crítico y políticas culturales en América Latina". Córdoba: Alción Editora.

Palermo, Zulma (2005) "La opción decolonial". Centro de Estudios y Actualización en Pensamiento Político, Decolonialidad e Interculturalidad. Disponible en http://www.ceapedi.com.ar/imagenes/biblioteca/libreria/201.doc

Quijano, A. (1989) “La nueva heterogeneidad estructural de América Latina”. En Sonntag, H. (ed.) ¿Nuevos Temas Nuevos Contenidos? Las Ciencias Sociales de América Latina y El Caribe ante El Nuevo Siglo. Caracas: Editorial Nueva Sociedad y UNESCO.

Quijano, A. (1992) “Colonialidad y modernidad-racionalidad” en Bonilla, H (ed.) Los conquistados. 1942 y la población indígena de las Américas. Bogotá: Tercer Mundo Editores.

Quijano, A. (2000) Colonialidad del poder, eurocentrismo y América Latina. En E. L. (comp.), La colonialidad del saber, eurocentrismo y Ciencias sociales. Buenos Aires: CLACSO.

Redfield, R. (1941) “The Folk Culture of Yucatán”. Chicago: University of Chicago Press.

Rodríguez, N. (2018). Problematizaciones en torno al concepto de universalidad: del eurocentrismo a la interculturalidad. Cuadernos De Humanidades, (29), 201-210. Recuperado de: http://humani.unsa.edu.ar/cdh/index.php/CDH/article/view/16

Rodríguez, N. (2020) Interculturalidad y Universidad: Desarrollo, avances y perspectivas del Proyecto de Tutorías con Estudiantes de Pueblos Originarios en la Universidad Nacional de Salta (Tesis de posgrado). Universidad Nacional de Tucumán. Facultad de Filosofía y Letras. 
Disputas de sentidos en las formas de habitar el mundo

Una propuesta conceptual para (re) pensar el hábitat en términos interculturales.

Rodríguez, R. (2010). “La diversidad cultural y la pretensión de universalidad del mundo moderno". Revista Estudios, CEA-UNC, 229-236.

Romero, G. (2008) “La cuestión de la participación en la construcción social del espacio habitable: viviendas, barrios, aldeas, pueblos y ciudades en México y América Latina". 1er Congreso Iberoamericano en teoría del Habitar "Iberoamerica una forma de habitar". San Juan, Argentina.

San Juan, G. y otros (2011) "Tecnología para la mejora del hábitat de agricultores familiares". La Plata: el autor.

Santos, B. (2003) “Crítica de la razón indolente: Contra el desperdicio de la experiencia. Para un nuevo sentido común: La ciencia, el derecho y la política en la transición paradigmática". Bilbao: Desclée

Santos, B. (2006) "Conocer desde el Sur. Para una cultura política emancipatoria". Fondo editorial de la Facultad de Ciencias Sociales UNMSM

Santos, B. (2009) “Una epistemología del Sur: la reinvención del conocimiento y la emancipación social”. México: Siglo XXI. CLACSO.

Santos, B. (2018) "Construyendo las Epistemologías del Sur: para un pensamiento alternativo de alternativas". Buenos Aires: CLACSO.

Sañudo Vélez, L. (2012) “La casa como territorio. Una nueva epistemología sobre el hábitat humano y su lugar doméstico". Iconofacto, Vol. 9, № 12, pp. $214-231$.

Segato, R. (2005) “En busca de un léxico para teorizar la experiencia territorial contemporánea". En Piazzini, C. (Comp.) (Des) Territorialidades y (No) lugares: procesos de configuración y transformación social de espacio. Medellín: INTER/Hombre Nuevo Editores.

Segato, R. (2018) "La crítica de la colonialidad en ocho ensayos". Buenos Aires: Prometeo libros.

Sosa Velásquez, M. (2012). “¿Cómo entender el territorio?”. Guatemala: Editorial Cara Parens.

Torrico Villanueva, E. (2013) “Luis Ramiro Beltrán y la Comuniucología de Liberación”. En Memoria Académica 2012. Sucre: ABOIC. Pp. 54-58. 


\section{Gonzalez Facundo}

Uranga, W. (2017) “La comunicación es acción: comunicar desde y en las prácticas sociales".

Obtenido de:

http://www.washingtonuranga.com.ar/index.php?option=com_content\&view=article\&i $d=16$ : propios-22\&catid=8:textos-propios\& $\mid$ temid $=107$

Valdéz, R. (2014). Producción social de Sentido acerca del Hábitat Popular. El caso del barrio La Victoria, en la periferia del Gran La Plata. La Plata: UNLP

Valdéz, R. (2014). Producción social de Sentido acerca del Hábitat Popular. El caso del barrio La Victoria, en la periferia del Gran La Plata. La Plata: UNLP

Vanoli, F., Martinez, V. y Cejas, N. (2018) “Procesos Comunicacionales en la producción social del hábitat: tres inflexiones para un abordaje decolonial". Questión , 26.

Vázquez Romero, J. M. (2009) “Los aportes de Henri Lefebvre a la Geografía urbana. Un corpus Teórico para entender las nuevas espacialidades". 12ํㅡㄹ Encuentro de Geógrafos de América Latina. Montevideo.

Veiga, D. (2009) “Desigualdades sociales y fragmentación urbana”. En Poggiese, H. y Cohen Egler, T. (comp.) Otro desarrollo urbano: ciudad incluyente, justicia social y gestión democrática. Buenos Aires: CLACSO

Viveiros de Castro, E. (2004) "Perspectival Anthropology and the Method of Controlled Equivocation". Tipití: Journal of the Society for the Anthropology of Lowland South America: Vol. 2: Iss. 1, pp. 3-22.

Walsh, C. (2010) “Interculturalidad Crítica y Educación Intercultural” en Viña, J.; Tapia, L. y Walsh, C. Construyendo Interculturalidad Crítica. La Paz: Instituto Internacional de Integración del Convenio Andrés Bello.

Walsh, C. (2014) “Interculturalidad y Colonialidad del Poder. Un pensamiento y posicionamiento otro desde la diferencia colonial”. En Mignolo. W. (Comp.) Interculturalidad, decolonización del estado y del conocimiento. Buenos Aires: Del signo.

Wirth, L. (1938) "Urbanism as a Way of Life: The City and Contemporary Civilization". American Journal of Sociology, 44.

Wittgenstein, L. (2003). “Tractatus logico-philosophicus". Madrid: Editorial Tecnos. 